\title{
A LEGALIDADE ESTRITA E SUA APLICAÇÃO FRENTE AOS PRINCÍPIOS DA PROPORCIONALIDADE E DA RAZOABILIDADE NO JULGAMENTO DAS PRESTAÇÕES DE CONTAS
}

\author{
José Ezequiel Albuquerque Bernardino ${ }^{1}$ \\ Carlos Marden Cabral Coutinho ${ }^{2}$
}

\section{RESUMO}

O presente artigo faz uma abordagem do uso indiscriminado dos princípios da proporcionalidade e da razoabilidade no julgamento dos processos de prestações de contas dos candidatos eleitorais na seara da Justiça Eleitoral, em detrimento das regras estabelecidas na própria legislação eleitoral, transitando por dois acórdãos paradigmas: um da instância ordinária e outro do Tribunal Superior Eleitoral. Tem-se, nesse percurso, um estudo crítico dos conceitos de proporcionalidade e razoabilidade sob a ótica do TSE e a sua conceituação na visão de Humberto Ávila. Cabe salientar que a presente pesquisa foi embasada em estudo bibliográfico e jurisprudencial do tema.

PALAVRAS-CHAVE: Prestação de Contas; Candidatos; Justiça Eleitoral; Princípio da proporcionalidade; Razoabilidade.

\section{STRICT LEGALITY AND ITS APPLICATION TO THE PRINCIPLES OF PROPORTIONALITY AND REASONABILITY IN ACCOUNTING JUDGMENT}

\begin{abstract}
This article deals with indiscriminate use of the principles of proportionality and reasonableness in judging the processes of accountability of electoral candidates in the area Electoral Justice, to the detriment of the rules established in the electoral legislation itself, through two paradigm judgments: one of the ordinary and other instances of the Superior Electoral Court. This section presents a critical study of the concepts proportionality and reasonableness from the point of view of TSE and its conceptualization in Humberto Avila's view. It should be noted that present research was based on a bibliographical and jurisprudential study of the theme.
\end{abstract}

KEYWORDS: Accountability; Candidates; Electoral justice; Principle of proportionality; Reasonability.

\section{CONSIDERAÇÕES INICIAIS}

\footnotetext{
1 Mestrando em Direito, Acesso à Justiça e ao Desenvolvimento pelo Centro Universitário Christus UNICHRISTUS. Assessor Jurídico do Tribunal Regional Eleitoral do Ceará. Bacharel em Direito pela Universidade de Fortaleza- UNIFOR. E-mail: ezequielbernardino7@gmail.com.

${ }^{2}$ Procurador Federal. Especialista em Direito Processual Civil e Mestre em Ordem Jurídica Constitucional pela Universidade Federal do Ceará. Doutor em Direito Processual pela Pontifícia Universidade Católica de Minas Gerais. Pós-doutor em Estado, Democracia e Constituição pela Universidade do Vale do Rio dos Sinos. Professor do programa de pós-graduação do Centro Universitário Christus - Unichristus.
} 
A frequência da argumentação utilizada pelas Cortes Eleitorais para aprovar ou rechaçar a apresentação das contas eleitorais (após o encerramento da atividade de campanha) pauta-se, não raro, pelos princípios da proporcionalidade e da razoabilidade, conceitos que entraram para o vocabulário jurídico brasileiro na década passada.

A abordagem do tema em curso será restrita à prestação de contas dos candidatos eleitorais que, para custear suas campanhas eleitorais, arrecadaram e aplicaram recursos, muitas vezes oriundos de si mesmo, mas também originários de doações físicas ou estimáveis em dinheiro de pessoas físicas, de outros partidos políticos e candidatos, da comercialização de bens, serviços ou promoção de eventos pelo candidato, etc.

Esta realidade, provisória ou tendente à falibilidade, tem como fonte hierárquica o Tribunal Superior Eleitoral, que tornou possível a aplicabilidade destes princípios desde que cristalizada pelo seguinte tripé: a) de que as falhas constatadas não possam comprometer a lisura do balanço contábil; b) a suposta irrelevância do percentual dos valores envolvidos em relação ao total arrecadado na campanha; e c) a ausência de comprovada má-fé dos candidatos com irregularidades.

Note-se que a imagem construída via interpretação dos tribunais pode refletir apenas uma parcela da realidade, que em determinado contexto histórico foi dada maior atenção ou ênfase a critérios definidos de maneira intersubjetiva; contudo, a cognição até então realizada pode perfeitamente cair no conto de desprezar, ainda que momentaneamente, outra parcela da realidade. Talvez esse tipo de enfoque parcial da realidade seja efetivamente inevitável em qualquer atividade humana, mas isso não significa que ele não tenha importantes impactos que merecem ser objeto de atenção.

Tanto isso é verdade que existem reclamações na doutrina assentando que o tema "prova" tem sido negligenciado, inclusive pelos que tratam da Teoria do Processo; bem como das especificidades dos Processos Civil e Penal, razão pelo qual aproveita-se a oportunidade para somar à reivindicação, no que diz respeito ao Processo Civil Eleitoral. Dentro de qualquer perspectiva adequada de processo democrático, a questão da prova assume uma importância crucial, na medida em que se relaciona com vários direitos fundamentais processuais, notadamente a fundamentação da decisão.

No que diz respeito ao tema Prestação de Contas, a fundamentação do provimento judicial nos princípios da razoabilidade e da proporcionalidade também se ressente de 
dificuldades para acolher a afirmação dos candidatos sobre a arrecadação e os gastos despendidos, uma vez que a relação entre prova e verdade deve ser direta e a mais clara possível. Efetivamente, um conceito de verdade processual é indissociável da existência de um conjunto probatório consistente.

A realidade não é algo fácil de ser perquirida com precisão, sempre dependendo de outros fatores para a construção da realidade momentânea, temporária, precária; contudo, de logo, abre-se um longo painel de alerta para não se enveredar para o extremo oposto da realidade provisória, em que não se tem certeza absoluta de nada, o ceticismo, sob pena da jurisdição autodeclarar-se falida na sua função de dizer o direito.

Desde já, apressa-se a revelar que não há nenhuma crítica a ser desfechada em desfavor de determinada corrente de julgadores na condução da sua apreciação judicial das Prestações de Contas; tratando-se apenas de observações, estudos focados nos julgamentos dos Tribunais Regionais Eleitorais.

De toda forma, não se pode afirmar com precisão inabalável ou irreversível a neutralidade dessas duas classes de julgadores, tal qual Benjamin Constant construiu em relação aos monarcas constitucionais como guardiães da Constituição, ou assim como caracterizou Schmitt (2007), com o seu pouvoir neutre como um órgão justaposto, "que não está acima, mas sim ao lado dos outros poderes constitucionais”.

Por isso, necessário repisar que não se cogita aqui de atribuição de eventual ilegalidade por parte das diversas classes dos juízes no julgamento dos processos judiciais de contas dos candidatos, quando da aplicação dos mencionados princípios. A abordagem crítica que se pretende está voltada à discussão construtiva de melhores práticas judiciais, especialmente no que dizem respeito às garantias das partes.

É curioso que, mesmo essa concepção tendo sido objeto de incerteza no século XVIII, até hoje perduram as mesmas discussões sobre esta temática, em que de um lado temse o automatismo, no qual o juiz não produz criativamente direito, mas apenas acha a decisão já confeccionada pela lei, pronta para vestir a controvérsia levada a juízo; de outro lado pulsa a ideia de que em toda decisão há um elemento de pureza que não pode ser extraído da essência da lei. 
Para enfrentar esse tema, será inicialmente dedicado um tópico para analisar algumas decisões da Justiça Eleitoral, focando naquelas onde os princípios da proporcionalidade e da razoabilidade foram utilizados como fundamentação da decisão. Na sequência, será estabelecida uma argumentação em torno da adequação da utilização desses conceitos indeterminados, com preocupação principal quanto a eventual excesso no recurso a esse tipo de motivação.

A título de conclusão, o trabalho apresentará um argumento no sentido de que é típico do Estado Democrático de Direito que as partes tenham direito a uma decisão fundamentada, construída a partir de argumentos que possam ser racionalmente controlados; o que acaba por ser prejudicado pelo uso excessivo de conceitos jurídicos indeterminados.

O processo é uma tecnologia que tem por objetivo proporcionar às pessoas um ambiente no qual elas possam resolver seus conflitos perante um terceiro imparcial, que lhes assegure contraditório e ampla defesa em um processo público, para proferir uma decisão fundamental em um prazo razoável. Este trabalho se propõe a demonstrar que tal objetivo é comprometido quando há recurso exagerado aos princípios da proporcionalidade e da razoabilidade.

\section{JULGAMENTO DOS PROCESSOS DE PRESTAÇÃO DE CONTAS}

Houve um tempo em que se discutiu sobre a natureza dos processos de Prestação de Contas. Superada esta fase, que considerava o procedimento de apresentação de contas como de natureza administrativa, vingou a alteração legislativa de 2009, confirmando-se o entendimento de que a natureza do processo de prestação de contas é de jurisdição voluntária, sendo diverso do processo litigioso, onde não se encontram as figuras antagônicas de uma relação processual como "autor" e "réu", nos termos da relação angular de Oskar Bülow (1964).

Tecidas estas primeiras ideias, impende-se destacar que antes a prestação de contas de campanha era regulada por uma lei editada para cada pleito; entretanto, encontra-se regida hoje pela denominada lei das eleições, Lei $n^{\circ}$ 9.504/97, e por uma resolução que sempre é editada para regular àquela determinada eleição. 
Nesse diapasão, as diretrizes normativas eleitorais estipulam uma série de limites que os candidatos não podem teimar desafiar; sob pena de terem o dissabor de receber um provimento judicial que desaprova a prestação de contas, face a verificação de falhas que comprometem sua regularidade.

Sendo assim, as restrições vão referir-se desde o total de gastos de campanha às doações realizadas por terceiros em benefício da campanha, ou às doações dos recursos próprios dos candidatos, às assunções de dívidas de campanhas, dentre outros. Trata-se, portanto, de uma ampla análise das contas envolvidas em vários aspectos da campanha eleitoral.

Com efeito, é nesse campo fértil onde os julgamentos que envolvem a aplicação dos princípios da razoabilidade e da proporcionalidade se fazem presentes. Não raro, costuma-se aprovar ou negativar o "acerto de contas", sob o argumento que determinado gasto ou despesa poderiam ser considerados regulares, porquanto estariam protegidos pelo manto da conceituação empregada a esses princípios pelos Tribunais Eleitorais. Eis o que se colhe das palavras da instância superior:

ELEICÕES 2014. AGRAVO REGIMENTAL - RECURSO ESPECIAL • PRESTACÃO DE CONTAS. CAMPANHA ELEITORAL • SERVIÇOS ADVOCATÍCIOS E CONTÁBEIS. AUSÊNCIA DE COMPROVANTES DE PAGAMENTO. ÚNICA FALHA APONTADA. APLICACÃO DOS PRINCÍPIOS DA PROPORCIONALIDADE E DA RAZOABILIDADE. PRECEDENTES. APROVACÃO DAS CONTAS COM RESSALVA. DESPROVIMENTO. 1. A ausência de apresentação dos comprovantes de pagamentos relativos aos serviços advocatícios e contábeis prestados no curso da campanha eleitoral, única irregularidade apontada pela Corte de origem, sem indicação da magnitude da irreguIaridade, com parecer do MPE e manifestação do órgão técnico regionaI peIa aprovação com ressalvas, não justifica a desaprovação das contas. 2. A jurisprudência desta Corte Superior é no sentido da aplicabilidade dos princípios da razoabilidade e da proporcionalidade no julgamento das contas de campanha, quando verificadas falhas que não lhes comprometam a regularidade. Precedentes. 3 . Agravo regimental desprovido. (AgR-Respe nO 6605-37/DF, Rel" Min. Luciana Lóssio, DJe de 12.8.2016 )

No mesmo sentido é a instância ordinária:

ELEIÇÕES 2016. RECURSO ELEITORAL. PRESTAÇÃO DE CONTAS DE CAMPANHA. CANDIDATA AO CARGO DE VEREADOR. APLICAÇÃO EM CAMPANHA DE RECURSOS PRÓPRIOS EM MONTANTE SUPERIOR À QUANTIA DO PATRIMÔNIO DECLARADO POR OCASIÃO DO REGISTRO DE CANDIDATURA. DISTINÇÃO ENTRE PATRIMONIO E RENDA. DEPÓSITO BANCÁRIO DEVIDAMENTE IDENTIFICADO. ÚNICA IRREGULARIDADE. OBSERVÂNCIA AOS DEMAIS REQUISITOS LEGAIS. 
LEI NO 9.504/97. RESOLUÇÃO TSE NO 23.463/2015. APROVAÇÃO COM RESSALVAS. MANUTENÇÃO DA SENTENÇA. DESPROVIMENTO DO RECURSO. 1. A sentença de primeiro grau firmou pela aprovação das contas com ressalvas, em razão de não haver elementos nos autos suficientes para atestar que houve de fato a utilização de recursos de origem não identificada, visto que o sistema leva em consideração apenas os bens patrimoniais declarados pelo candidato em seu registro de candidatura, sem considerar, por exemplo, a existência de recursos provenientes de seu trabalho. 2. Este colendo Tribunal, por diversas vezes, apreciando processos deste jaez, já se debruçou sobre a questão da ausência de declaração de bens na fase do registro de candidatura em relação à existência de recursos próprios aferidos na prestação de contas, e nesse contexto foi repetido, em diferentes ocasiões, a distinção dos conceitos entre patrimônio e renda. Assim, restou consolidado que a declaração de bens apresentada, quando do registro de candidatura, não sinaliza, de forma categórica, a condição econômica do candidato. 3. No caso dos autos é incontroverso que a prestadora de contas não declarou bens patrimoniais em seu registro de candidatura, contudo no respectivo registro informou que exercia a atividade de dona de casa, sendo crível, tomando como parâmetro à época das eleições de 2016, que esta tenha acumulado a quantia de R\$ 590,00, para ser utilizada na sua campanha eleitoral, sem que isso possa configurar a realização do chamado "CAIXA 2". 4. Nesse contexto, entendo que, na espécie, o valor de $\mathrm{R} \$ 590,00$, empregado na sua campanha eleitoral a título de recursos próprios, não se trata de receita de origem não identificada, apresentando a recorrida, a meu ver, condições para custear parte das despesas de campanha, inclusive o valor não é exabundante e pode ter procedido como produto de suas economias. 5. Quanto à tese levantada pelo recorrente de que os recursos provenientes do trabalho, existentes em conta bancária ou dinheiro em espécie, deveriam ser declarados no registro de candidatura, não prospera, uma vez que a Resolução TSE n.o 23.455/2015, que dispõe sobre a escolha e o registro de candidatos nas eleições de 2016, não elenca entre a documentação necessária a reclamada desincumbência. 6. Com efeito, tem-se por acertada a decisão de primeiro grau, visto que a única falha apontada não comprometeu a regularidade da prestação de contas, razão pela qual deve-se manter a sentença que as julgou aprovada com ressalvas, nos termos do art. 68, inciso II, da Resolução TSE n.o 23.463/2015. 7. Recurso conhecido e desprovido. (TRE-CE, Recurso Eleitoral n. ${ }^{\circ}$ 327-09.2016..6.06.0098, Rel. Juiz Roberto Viana Diniz de Freitas, pub. DJE do TRE/CE n. ${ }^{\circ}$ 120, p. 32, em 4.7.2018)

Nota-se, portanto, que a legislação eleitoral, quando do julgamento das contas de campanha, demonstra sua incompletude legiferante face à inexistência de critérios normativos suficientes para definir, objetivamente, o que será tido como erros materiais irrelevantes ou o que seja erro formal, para fins de proferir julgamento pela aprovação, aprovação com ressalvas ou desaprovação.

De fato, o término da atividade legislativa, no caso específico, terá que contar com a atividade judicial para continuar e aprimorar a aplicação da lei, antes iniciada com sua positivação, e, assim, realizar a ordem legal por meio do raciocínio desenvolvido pelo Judiciário, num claro exercício de atividade mental, sopesando no caso concreto, quando efetivamente estará configurada a ocorrência do erro material irrelevante ou do mero erro formal. 
Nesse cenário, os julgamentos dos tribunais regionais reiteram o julgamento proferido pelo Tribunal Superior Eleitoral, repetindo o entendimento, por exemplo, de que verificada uma única irregularidade na prestação de contas do candidato, não haveria o condão de rechaçar a veracidade de determinada documentação e, por conseguinte, desaprová-la.

A tensão que deveria atormentar a atividade judicial, pelo espaço cedido pelo Legislativo, no seu raciocínio de atividade mental de aplicação da proporcionalidade e da razoabilidade ao caso concreto, não seria inversa à prática realizada hoje?

Numa análise integrativa, tem-se que os significados das regras estabelecidas pelas normas eleitorais, não impede que estes mesmos valores tenham autonomia para permitir condutas diversas, desde que respeitados valores fundamentais, que o princípio democrático deles não se pode desgarrar.

Convivemos com uma infinidade de questionamentos sobre a moralidade na política; notícias de corrupção, prática do famigerado caixa dois, em que a sociedade anuncia não ser consentânea com o mínimo de irregularidade que possa se atrelar ao candidato almejante de eventual mandato político.

Nesse sentido, até a imprensa internacional, como o jornal espanhol El País (2019), dá conta de pequenos atos de protestos realizados em várias cidades do Brasil, motivados pela decisão do STF de que a Justiça Eleitoral tem competência para julgar casos de corrupção e lavagem de dinheiro, desde que atrelados ao caixa dois.

Sem prejuízo da importância dessas pautas, o Direito pátrio reconhece a existência do Princípio do Juiz Natural, de forma que é aceita a importância de que as pessoas sejam julgadas por determinadas autoridades e não por outras. Nesse cenário, adquire especial relevância a definição da competência do juízo, notadamente quando se trata de uma justiça especializada, cujas decisões regularmente recorrem a conceitos jurídicos indeterminados.

\section{HÁ EXCESSO NO USO DA PROPORCIONALIDADE E DA RAZOABILIDADE NO JULGAMENTO DAS PRESTAÇÕES DE CONTAS ELEITORAIS DOS CANDIDATOS?}


No tocante à prestação de contas, põe-se em xeque as decisões judiciais que percorram destino diverso da previsão específica da lei, quando no juízo de valoração da documentação apresentada pelos candidatos na prestação de contas, abandona-se à aplicação direta da norma ao caso concreto, optando pela manipulação da discricionariedade quanto à aplicação dos princípios da proporcionalidade e da razoabilidade, porque eles seriam mais justos do que a lei.

Seria este o real sentido da proporcionalidade e da razoabilidade? Poderia se falar de uma prática excessiva dos julgadores, no trato da prestação de contas, de abuso no uso dos princípios da proporcionalidade e da razoabilidade?

A despeito da ferida exposta, compartilho semelhante preocupação de expoente do âmbito jurídico, Grau (2018, p. 21):

\begin{abstract}
A partir da segunda metade dos anos de 1980, desde leituras de Dworkin, passamos a ser vítimas dos princípios e dos valores". E prossegue afirmando que os "Os juízes despedaçam a segurança jurídica quando abusam do uso de 'princípios' e praticam fazem-no cotidianamente! _ os controles da proporcionalidade e da razoabilidade". Acrescenta o Jurista: arremata: "Enquanto a jurisprudência do STF estiver fundada na ponderação entre princípios_isto é, na arbitrária formulação de juízos de valor _ a segurança jurídica estará despedaçada". E arremata: Por isso tenho medo dos juízes e dos tribunais que praticam esse inusitado controle de proporcionalidade e de razoabilidade das leis, legando-me incerteza e inseguranças jurídicas.
\end{abstract}

De evidenciar, por isso, que sobre a investigação dos critérios em que se palmilham a utilização dos princípios não pode cair a pecha do ostracismo, tal obscuridade deve sair do anonimato ou do estado fático da exclusão, para revelar a proteção dos valores que se almeja favorecer, o sopesamento e as ponderações aplicáveis ao caso concreto. Neste sentido, a percepção de (ÀVILA, 2005, p. 56) demonstra o zelo na trativa do melindre da questão, quando assinala:

Sobre essa questão, vem à tona o modo como os princípios são investigados. E,
nessa matéria, é fácil encontrar dois modos opostos de investigação dos princípios
jurídicos. De um lado, podem-se analisar de modo a exaltar os valores por eles
protegidos, sem, no entanto, examinar quais são os comportamentos indispensáveis
à realização desses valores e quais são os instrumentos metódicos essenciais à
fundamentação controlável da sua aplicação.

Na verdade, a problemática não é nenhuma novidade, tanto é que Rui Barbosa, ainda no século passado, num estudo comparado da Suprema Corte Americana, manifestou que a 
noção concreta da discricionariedade é definida pela noção abstrata de poder meramente político. A despeito de maior esclarecimento do jurista Rui Barbosa (1983, online), vejamos:

\begin{abstract}
No caso Marbury v. Madison a Corte Suprema definiu com extraordinária força e lucidez as balizas da autoridade respectivamente distribuída aos três ramos do Governo. Então se demonstrou que todo ato legislativo, repugnante à Constituição, deve ser desprezado pelos tribunais como nulo: que os funcionários administrativos podem ser compelidos pelo Poder Judiciário a cumprir os deveres, que lhe foram explicitamente impostos, e não envolverem faculdade discricionária (and not involving official discretion); porquanto, disse o tribunal, o Governo dos Estados Unidos é um governo de leis, não de arbítrio pessoal (a government of laws and not of man), e a alçada judicial decide sobre direitos individuais, não lhe competindo liquidar questões de seu natural políticas, intrometendo-se em assuntos encarregados, pela Constituição, ou pelas leis, ao critério (to the discretion) de outro poder.
\end{abstract}

Percebe-se então que diante do expresso prognóstico da Lei n. ${ }^{\circ}$ 9.504/97, de que o pedido de registro de candidato deva ser instruído com a respectiva declaração de bens assinada pelo candidato, não há ambiente propício para considerar adequada a aplicabilidade dos princípios da proporcionalidade e da razoabilidade no âmbito da prestação de contas para aquele candidato que declarou não possuir sequer um bem registrado em seu nome.

A dinâmica apresentada, não significa dizer que diante da positivação das disposições mencionadas, decorra necessariamente a impossibilidade de encontrar comportamentos que negam a estrita legalidade, desde que tracejado dentro de um contexto de aplicabilidade racional dos valores refutados.

No que pese a distinção rotineiramente realizada pelos tribunais regionais entre o conceito de patrimônio e renda, no sentido de que a ausência de declaração de bens no registro de candidato, categoricamente, não sinalizaria a condição econômica do candidato; trata-se de ilação surreal, ou seja, efetiva intromissão no assunto encarregado à Lei $\mathrm{n}^{\circ}$ 9.504/97, que, no entanto, o corpo de julgadores, utilizando-se do critério discricionário, vai além dos limites traçados pela legislação eleitoral.

A valer, não se trata a análise de mera interpretação subjetiva levada a efeito pelo magistrado; igualmente não se cuida de uma avaliação em por uns se toma como supérflua, enquanto por outros têm-se como prioritário.

De modo que é perfeitamente compreensível a crítica relacionada ao abuso no uso dos princípios da razoabilidade e da proporcionalidade na definição dos julgamentos nas prestações de contas, uma vez que é a própria lei eleitoral que define a necessidade da 
apresentação da declaração de bens no momento em que o candidato requer o seu registro de candidatura.

Se o sentido deste dispositivo em epígrafe não fosse o de indicação da existência de bens tanto materiais como pecuniários, a lei poderia ser fadada à omissão; natureza inerente às leis mortas, desprovidas de finalidade.

Com efeito, o uso da proporcionalidade e da razoabilidade na espécie significa a intromissão do Poder Judiciário em espaço onde a norma não lhe cedeu nenhuma expectativa para o exercício da função judicial; a qual, cotidianamente, pratica sob a justificativa de exarar um direito que seria mais adequado que a lei. Sem entrar em questões de mérito, o problema é que (em um Estado de Direito) a fonte da lei importa e ela deve ser o Poder Legislativo.

Bem por isso, a consequência do uso indevido do critério da discricionariedade nos casos desse jaez incidirá na geração de incerteza jurídica; porquanto, a atividade judicial, quando da formulação dos juízos de valores, foi manejada à revelia da lei, com nítido requinte de arbitrariedade; uma vez que não foi acionada para isso.

De modo que não é utopia asseverar que em detrimento do juízo de ponderação elaborado pela atividade judicial para determinar o alcance dos princípios da proporcionalidade e da razoabilidade; deverá ser prestigiada a aplicabilidade da norma àquele fato deduzido em concreto, sob pena de eliminar o seu núcleo essencial. Tanto quanto for possível, o processo precisa de uma prática que prestigie os fatos.

Para melhor esclarecimento do uso dos princípios da proporcionalidade e da razoabilidade no julgamento das prestações de contas dos candidatos, colhe-se do site de pesquisa de jurisprudência do Tribunal Regional Eleitoral do Ceará, que em termos quantitativos, no período de 2016 a 2019, em 43 acórdãos da relatoria de juízes da classe dos juristas, foram utilizados a ponderação dos princípios em destaque; enquanto que a classe dos magistrados de carreira perfizeram a somatória de 81 julgamentos.

De fato, antes que se imagine a adoção de uma perspectiva liberal destas considerações, é necessário ilustrar que a utilização dos princípios da razoabilidade e da proporcionalidade nesse número considerável de acórdãos pode destoar do sentido exclusivo 
inicial da vinculação estrita do aparelho judicial do Estado à vontade legislativa do povo, nos moldes da concepção de John Locke (1966) .

No entanto, com pensamento crítico e resistente à legalidade estrita, Ingeborg Maus (2000) assevera que a introdução dos pontos de vista morais e de "valores" na jurisprudência, não só lhe confere maior grau de legitimação, imunizando suas decisões contra qualquer crítica, como também conduz a uma liberação da Justiça de qualquer vinculação legal que pudesse garantir sua sintonia com a vontade popular.

Com efeito, independente da posição que venha prevalecer, seja a atividade autônoma da "interpretação judicial”, seja a vontade do povo por meio do Parlamento, devese levar em conta sempre o preceito constitucional da prestação de contas eleitorais acompanhado dos seus inseparáveis princípios norteadores a saber: legalidade, efetividade, verdade material, transparência, lisura, dentre outros.

Nesta esteira de ideias, o questionamento que não quer emudecer diz respeito a saber se esta autonomia judicial na interpretação da razoabilidade e na proporcionalidade no juízo das prestações de contas encontra-se permeado pelos princípios simpáticos à participação democrática do poder, ou se o que acontece nos "bastidores" da vida real seria a relativização da norma, por meio de ponderações que vão de encontro ao que foi delegado pelo povo ao Parlamento.

Sob outro ângulo, ainda padece a dúvida se o déficit democrático, inerente das decisões judiciais, teriam autoridade para relativizar os valores da legalidade, da efetividade, da verdade material, da transparência e da lisura na prestação de contas.

No que pese a imperfeição do processo democrático, no que se refere a forma de acesso do corpo de julgadores dos tribunais eleitorais, com sua composição diversa; poder-seia tolerar juízos de valores, especificamente quanto à proporcionalidade e à razoabilidade na prestação de contas, destoantes dos preceitos firmados pela Constituição?

A dificuldade para digestão da autonomia da atividade judicial nessas questões pode ser tolerada frente a todos esses valores firmados na Constituição pelo Parlamento?

Essas reflexões não devem dar margem para o surgimento de mais um ponto cego do Direito (MARTINS, 2013), deixando as indesejáveis lacunas no campo jurídico; pois ainda que não se tenha resposta precisa e imediata, necessário se faz a construção de uma ideia pelo 
menos mais consentânea, uma vez que a higidez dessa fase do processo eleitoral, qual seja, o processo de prestação de contas, tem relação direta com o exercício da democracia.

A proposição exposta, roga-se não ser compreendida numa acepção heurística, em que a distinção entre as regras e princípios são efetuadas pelo magistrado, que entravado pelo objeto da sua apreciação, não consegue demonstrar o verdadeiro significado da legislação eleitoral.

Não há que se duvidar, portanto, do destino que a norma deve tomar, porquanto o trajeto a ser percorrido já tem destinatário identificado: a democracia numa acepção ampla, com parada obrigatória na transparência, na lisura e na legitimidade das eleições.

De sorte, que a conclusão a que se permite chegar é que aos dispositivos reservados à matéria da Prestação de Contas, não se sirvam de pretexto para exclusão das regras, em detrimento da existência de princípios, que no caso concreto, favoreça situações casuísticas e desprovidas de racionalidade.

Realmente a questão não pode quedar-se à margem da discussão não só no ambiente judicial, pois, também merece destaque das mesas acadêmicas ao tratar dos problemas jurídicos, sociais e políticos, sob pena de submeter tal matéria ao detestável contorno da incerteza, isso certamente porque a democracia não comporta mais uma ambiguidade dentre as que são atribuídas por quem a renegam.

\section{CONCLUSÃO}

O instituto da Prestação de Contas constitui o instrumento oficial que permite a realização de contrastes e avaliações, bem como o controle financeiro do certame. Esse controle tem o sentido de perscrutar e cercear o abuso de poder, notadamente o de caráter econômico, conferindo-se mais transparência e legitimidade às eleições.

Nesse quadrante, a preocupação com a lisura da prestação de contas se faz necessária; porquanto se trata de tema central da vida democrática, a escolha dos detentores de mandato político. 
Indubitável, portanto, que a legitimidade do processo de eleição destes candidatos se confirma pela transparência na prestação de suas contas, que servirá de instrumento para verificação de eventual vício que macule a atuação do próprio candidato eleito.

Na mesma linha do que já se expôs, deve repisar-se que o TSE, debatendo a matéria da transparência na prestação de contas, asseverou que o sistema democrático e o modelo republicano consagram, como fórmula legitimadora do exercício do poder, o direito do cidadão à plena informação sobre a origem dos recursos utilizados nas campanhas eleitorais, especialmente nas hipóteses de escolha, em processo eleitoral, daqueles que irão, como membros do Poder Legislativo ou do Poder Executivo, coparticipar da regência e da direção superior do Estado.

Desta forma, a importância da transparência e da lisura da prestação de contas, vistas como termômetro de verificação da legitimidade do processo democrático, não pode ser banalizada pela autonomia judicial no trato de questões de natureza indiscutivelmente política, uma vez que se refere ao exercício do poder.

Decorre desta ilação a conclusão de que o julgamento das prestações de contas tem natureza política, exatamente porque se refere ao exercício do poder; no entanto, isso não significa a inviabilização da correta aplicabilidade da legislação eleitoral ao caso concreto, nos moldes traçados pelo sistema democrático e o modelo republicano.

O uso da proporcionalidade e da razoabilidade nesta temática deverá ser empregado somente em casos excepcionais, dada a natureza política da prestação de contas, sob pena do processo de prestação de contas perder a capacidade de documentar a real movimentação financeira e, por consequência, obstruir o cumprimento pela Justiça Eleitoral da relevante competência estabelecida no art. 17, III, da Constituição Federal de 1988.

Por esse motivo é de se observar que o zelo com a ética da Prestação de Contas, aqui empregada, não se equipara, nem de longe, com a concepção utópica de política, tal qual a república imaginária de Platão, apenas no plano ideal. Sugere-se, portanto, o manuseio judicial com essa questão dentro do contorno realista do pensamento de Maquiavel (2007), com uma análise mais efetiva sobre a realidade da prestação de contas do que como poderia se imaginar no plano do dever ser. 
Consequência disso é que, no julgamento do prestador de contas, não se pode valorar a proporcionalidade e a razoabilidade tendo apenas como limite a concepção limitante traçada pelo TSE, de que as falhas não possam comprometer a lisura do balanço contábil, irrelevância do percentual dos valores envolvidos em relação ao total arrecadado ou ausência de comprovada má-fé.

De resto, merece destaque que a obediência à legalidade estrita no tema Prestação de Contas deve ser compreendida como instrumento que favorece ao cidadão e à democracia, daí porque não combina a flexibilização da legalidade por meio dos princípios da proporcionalidade e da razoabilidade.

Nesse diapasão, a instância superior, quando do emprego dos postulados constitucionais, não aparenta haver perpassado pela análise comparativa obrigatória dos subprincípios, tais como a adequação (fumaça do bom direito), a necessidade (perigo da demora), ou a proporcionalidade em sentido estrito (irreversibilidade); gerando crítica à construção deste desenho de modelo de decisão judicial, copiosamente repetido pelos tribunais regionais ao se afastarem da real movimentação financeira dos gastos eleitorais realizados.

Nesse sentido, tomando como parâmetro o acórdão citado pelo TRE/CE, em que o candidato disse, quando foi requerer a sua candidatura, não ser detentor de nenhum patrimônio; qual a evidência de que a documentação apresentada por este candidato poderia significar a condução de um bom direito?

A indagação, na espécie, não pode optar por responder tal questionamento de forma positiva, sob pena do princípio da proporcionalidade acabar por desnaturar a sua função instrumental de controle estatal.

Tem-se, portanto, uma inadequação entre o meio e o fim da probidade necessária, no tocante aos gastos de campanha por parte dos candidatos, eleitos ou não.

Ademais, na comparação de perdas e ganhos não há nenhuma vantagem para a Justiça Eleitoral referendar as contas de candidato com base num juízo de proporcionalidade, passível de críticas, ainda que o senso comum judicial seja o de valorar a proporcionalidade de forma inversa ao sufrágio popular manifestado nas urnas. 
Com efeito, o abrigo de tais julgamentos em nada contribui para a educação de cidadania, muito menos para a continuidade da salutar convivência democrática.

Por essa razão, selar o julgamento da prestação de contas composta da utilização diuturna dos princípios dentro dessa moldura em comento, significa atestar a existência de um processo eleitoral em que não se conseguiu realizar a vontade popular.

Há de alertar-se, à vista disso, que a relutância do indiscriminado uso da proporcionalidade e da razoabilidade, nos termos aqui expostos, certamente ensejará o enfraquecimento do controle da Justiça Eleitoral para com a contabilidade dos gastos de campanha dos candidatos.

Ao continuar esse raciocínio, qual seria o conceito da "necessidade" empregado para não desaprovar ou aprovar com ressalvas as contas de um candidato, que por mais que se diga que se trate de suposição impossível de real comprovação, atentou contra a transparência da prestação de contas?

Impende-se registrar, quanto a esta perspectiva, que a pretensão de suavizar a responsabilidade do prestador de contas somente poderá se dar considerando minimamente as condições excepcionalíssimas de cada caso concreto; ou seja, não pode ser a regra, tal qual os tribunais passaram a adotar.

De forma que o terceiro viés, a proporcionalidade em sentido estrito, igualmente demonstra carência de caracterização, uma vez que não há vantagem em confirmar a probidade da apresentação de uma prestação de contas desalinhada com a lisura exigível na prestação de contas.

Há de se concluir, por fim, que deitadas as premissas com base no uso indiscriminado dos princípios da proporcionalidade e da razoabilidade em sede da verificação da regularidade das prestações de contas eleitorais, estar-se-á adentrando dedutivamente numa forma de argumentação inválida de decidir. Isso porque não se pode imaginar o desenvolvimento da democracia sem antes passar por um processo eleitoral manejado de forma regular, cujo pré-requisito necessariamente transita pela verificação da prestação de contas hígida.

Importante destacar que não basta que a decisão judicial seja logicamente organizada, de forma que faça sentido para o leitor. A fundamentação da decisão é um direito 
fundamental processual das partes e um dever do magistrado, de forma que se impõe também a construção de uma decisão judicial que seja racionalmente controlável. Sendo assim, tem-se que é indevido o recurso exagerado aos conceitos jurídicos indeterminados, aí incluídos os princípios da proporcionalidade e da razoabilidade.

Nesse sentido, são essas as reflexões propostas quanto ao julgamento das prestações de contas eleitorais, dada a relevância da escorreita aplicação da legislação eleitoral na averiguação da legitimidade do processo democrático. Trata-se de uma pequena contribuição no sentido de aumentar a efetividade das garantias processuais e evitar o avanço do arbítrio que eventualmente perpassa as barreiras judiciais.

\section{REFERÊNCIAS}

ÁVILA, Humberto. Teoria dos princípios, da definição à aplicação dos princípios jurídicos. Malheiros Editores, 2005.

BARBOSA, Rui. O direito do Amazonas ao Acre Setentrional. Fundação Casa de Rui Barbosa: Rio de Janeiro, 1983.

BRASIL. Constituição (1988). Constituição Federal de 1988. Brasília, Disponível em: http://www.planalto.gov.br/ccivil_03/constituicao/constituicao.htm. Acesso em: 11 jun. 2019.

BRASIL. Decreto-Lei no 3.689, de 03 de outubro de 1941. Código de Processo Penal. Rio de Janeiro, 03 out. 1941. Disponível em: http://www.planalto.gov.br/ccivil_03/decretolei/del3689.htm. Acesso em: 11 jun. 2019.

BRASIL. Lei no 10.406, de 10 de janeiro de 2002. Código Civil. Brasília. DF: Presidência da República. Disponível em: http://www.planalto.gov.br/ccivil_03/leis/2002/110406.htm. Acesso em: 28 maio 2019

BRASIL. Lei n 9 9.504, de 30 de setembro de 1997. Lei das Eleições. Brasília, 30 set. 1997. Disponível em: http://www.tse.jus.br/legislacao/codigo-eleitoral/lei-das-eleicoes/lei-daseleicoes-lei-nb0-9.504-de-30-de-setembro-de-1997. Acesso em: 11 jun. 2019.

BRASIL. Tribunal Regional Eleitoral. Recurso Eleitoral no 327-09.2016..6.06.0098. Promotor Eleitoral. Geane Vasconcelos Vera. Relator: Juiz Roberto Viana Diniz de Freitas. Fortaleza, CE de 2018. Decisão Monocrática. Fortaleza, 2018. Disponível em: https://www.jusbrasil.com.br/processos/164342762/processo-n-327-0920166060098-do-trece. Acesso em: 11 jun. 2019.

BRASIL. Tribunal Superior Eleitoral. Agravo Regimental no 660537. Relator: Luciana Christina Guimarães Lóssio. Decisão. Brasília, 12 ago. 2016. Disponível em: 
https://tse.jusbrasil.com.br/jurisprudencia/373075058/recurso-especial-eleitoral-respe660537-brasilia-df?ref=serp. Acesso em: 11 jun. 2019.

BÜLOW, Oskar von. La teoria de las excepciones procesales y los presupuestos procesales. Buenos Aires: Ediciones Jurídicas Europa - América, 1964. Traducción de Miguel angel Rosas Lichtschein.

GRAU, BRASIL Eros Roberto. Por que tenho medo dos juízes: a interpretação/aplicação do Direito e os principios. 9. ed. São Paulo: Malheiros, 2018.

LOCKE, John. Two treatises of civil government. New York: Carpenter, 1966.

MAQUIAVEL, Nicolau. Discursos sobre a primeira década de Tito Livio. São Paulo: Martins Fontes, 2007.

MARTINS, Rui Cunha. O ponto cego do Direito: the Brazilian lessons. 3. ed. - São Paulo: Atlas, 2013.

MAUS, Ingeborg. Judiciário como superego da sociedade: o papel da atividade jurisprudencial na "sociedade órfã". São Paulo: Novos Estudos, 2000. Disponível em: http://www.direitocontemporaneo.com/wp-content/uploads/2014/02/JUDICI\%C3\%81RIOCOMO-SUPEREGO-DA- SOCIEDADE.pdf. Acesso em: 18 jun. 2019.

PAÍS, El. Grupos vão às ruas protestar contra o STF: Pequenos atos foram realizados em várias cidades do país contra decisão que, segundo eles, enfraquece a Lava Jato. 2019. Disponível em: https://brasil.elpais.com/brasil/2019/03/17/politica/1552848449_748579.html. Acesso em: 11 jun. 2019.

SCHMITT, Carl. O guardião da constituiçãa. Belo Horizonte: Editora del Rey, 2007. 